Article

\title{
Features of emotional sphere of adolescents of different ethnic groups of northeast Russia
}

\author{
Tatiana P. Bartosh ${ }^{1 *}$, Olga P. Bartosh ${ }^{2}$ \\ ${ }^{1}$ Scientific Research Center «Arktika», Fareastern Branch of the Russian Academy of Sciences, Karl Marx Str. \\ 24, Magadan, 685000, Russia; tatiana.bartosh@spbpo.ru \\ 2 Scientific Research Center «Arktika», Fareastern Branch of the Russian Academy of Sciences, Karl Marx Str. \\ 24, Magadan, 685000, Russia; olga bartosh@inbox.ru \\ *Correspondence: tatiana.bartosh@spbpo.ru; Tel.: +79148673553
}

\begin{abstract}
The combined ecological, geophysical, climatic, and social factors of the Northeast of Russia influence the organism from the early childhood being too intense for the functional systems. The purpose of the research is to study the emotional characteristics of adolescents of different ethnic groups in the northeast of Russia. Presented in the paper are results of the study that covered 826 adolescents (445 females and 381 males) at the age of 15-17, different by ethnic origin. We used standard methods of psycho-diagnostics. Our study has showed that the formation of the adolescents' emotional sphere in the North is undoubtedly influenced not only by the climatic and socio-economic environmental factors but also by ethnic features. There are intergroup differences in the aggressiveness profile of older adolescents living in the remote settlement vs. the regional center. It is shown that high school students in the remote settlement of Evensk, compared to their peers in Magadan, regardless of gender and ethnicity, are characterized by more pronounced hostile and auto-aggressive reactions. In adolescents of the Aboriginal population, as compared with their age mate Caucasians, the indicators of impairment in the field of Neuro Psychic Adaptation, Situational and Personal Anxiety, and Social Frustration are significantly more pronounced.
\end{abstract}

Keywords: adolescents; emotional sphere; ethnic-related peculiarities; North

\section{Introduction}

The adolescent age is characterized by an increase in the tension of regulatory mechanisms due to morphofunctional and neuroendocrine changes in the body [1]. Almost all functional changes in the emotional sphere lead to mental imbalance and conflict, reaction to surrounding people opinions is exacerbated, resentment and chronic dissatisfaction are increased. Frustration which is mainly associated with unfavorable parenting and intra-family relationships [2-3] often strengthens children's aggressive reactions to completely normal and "non-dangerous" situations that any child encounters from time to time forming their disadaptive mechanisms of interaction with the environment. The reaction to frustration manifests itself in anxiety, self-doubt, irritability and aggressiveness. Passive aggression often leads to mental disorders as risk factors for suicide [1]. Prerequisites for auto aggression are the disharmonious family environment of personality formation with a system of formal execution of social roles, emotional deprivation, intra-family aggression, and alcohol abuse [4-5]. Borderline mental disorders which are considered as a consequence of the disturbance of mental adaptation take the main place in the structure of mental pathology in children and adolescents [6-7].

Human habitation in remote inaccessible settlements of the North features social and economic difficulties, relative information isolation, large distances between settlements, poor transport mastery, inadequate medical care and a shortage of medical professionals, which also affects the morphofunctional and psychophysiological development of children and adolescents [4]. The combined ecological, geophysical, climatic, and social factors of the Northeast of Russia influence the organism from the early childhood being too intense for the functional systems, the central 
nervous system, and the mental sphere of the developing organism [3, 8, 9]. As it is known, adaptive resistance to extreme climatic and geographical factors is provided by increased functional activity of the right hemisphere of the brain whereas the left hemisphere of the brain responds to the effectiveness of social adaptation [8-9]. Nowadays a stable population of young Caucasians mainly belonging to the 1-3 generation of the newcomers has been formed in Magadan Region. The discrepancy of modern social requirements to the inner world of indigenous peoples causes their high social vulnerability [9-12]. Changing the stereotype of life and the coordinate system of values leads people with low stress resistance to psychosocial disadaptation as a risk factor for psychosomatic, psychiatric disorders, and depression. The different types of non-constructive behavior of these individuals are most often manifested in the form of aggression, autoaggression, or "self-destructive" suicidal behavior [10, 13-14, 15-16].

Semyonova [17], among the causes of high suicidal activity of the North and Siberia indigenes, considers the ethnic characteristics of the emotional sphere and emotional response in stressful situations as well as a low tolerance to stress factors. In the genesis of suicidal behavior of note are biological, clinical, individual-personal and socio-environmental factors [18-21]. Of note that 15-17 year-old adolescents demonstrate the greatest number of both uncompleted suicide attempts and suicidal deaths $[12,17]$.

The purpose of the research is to study the emotional characteristics of adolescents of different ethnic groups in the northeast of Russia.

\section{Materials and Methods}

The survey involved 826 adolescents of Magadan Region both boys and girls aged 15-17. Among them were 445 girls and 381 boys. The adolescents were divided into three groups: the 1st group were Aborigines (Koryaks and Evenes) in the town of Evensk in Magadan Region (154 girls and 108 boys); group 2 were Caucasians born in the region in the 1-2 generations living in the settlement of Evensk of Magadan Region (113 girls and 105 boys); and the 3rd group were Caucasians born in the region and residing in the city of Magadan (178 girls and 168 boys). Subjects of groups 1 and 2 were students of the boarding school in the settlement of Evensk of Magadan Region. In the city of Magadan students from grades 9-11 of three gymnasiums were surveyed.

The level of Situational (SA) and Personal (PA) Anxiety was determined by the Spielberger-Khanin technique. The presence of neurotic and neurosis-like symptoms in the emotional-affective sphere of adolescents was determined using the scale of Neuro Psychic Adaptation (NPA) [22]. The NPA test included 26 statements reflecting neurotic and neurotic-like manifestations in the emotional-affective sphere. More than 30 points on the scale of the NPA corresponded to the unfavorable prognostic signs of the disturbance of the Neuro Psychic Adaptation. The Level of Social Frustration of Adolescents $\left(\right.$ LSF $\left._{\text {Adol }}\right)$ was determined by the methodology of the LSFAdol. The questionnaire included 20 aspects of personal and social relationships. The subjects assessed their satisfaction of the relationships on a five-point scale (the Methodology was developed by a team of researchers led by L. I. Vasserman, St. Petersburg Institute of Behavior Care named after V. M. Bekhterev). Hostile and aggressive reactions the Bass-Darkey questionnaire were studied.

The survey was conducted with the subjects' informed consent in compliance with the requirements of the Helsinki Declaration and the approval of the Regional Ethical Committee for Biomedical Research at the Northeast Research Center for Far Eastern Studies (Protocol No. 3 of 04.12.2013).

Statistical processing of the data was carried out using the licensed application packages of Excel 97 and Statistika 10. The normal distribution of the measured variables was checked based on the Shapiro-Wilk test. Zero hypotheses were rejected at the level of significance of the corresponding statistical criterion of $\mathrm{p}<0.05$. For each parameter studied, the arithmetic mean $(\mathrm{M})$ and the representativeness error of the mean $(\mathrm{m})$ were calculated. To compare the variation series, Student's $\mathrm{t}$-test was used in assessing the confidence level of $\mathrm{p}<0.05$. 


\section{Results}

The results presented in Table 1 and Figure 1.

Table 1. Emotional indicators of the adolescents from different groups of the northeast of Russia

\begin{tabular}{|c|c|c|c|c|c|c|}
\hline \multirow[t]{2}{*}{ Indicator, points } & \multicolumn{2}{|c|}{$\begin{array}{c}\text { Group 1, Evensk } \\
\text { Aborigines }\end{array}$} & \multicolumn{2}{|c|}{$\begin{array}{c}\text { Group 2, Evensk } \\
\text { North born Caucasians }\end{array}$} & \multicolumn{2}{|c|}{$\begin{array}{c}\text { Group 3, Magadan } \\
\text { North born Caucasians }\end{array}$} \\
\hline & Females & Males & Females & Males & Females & Males \\
\hline $\begin{array}{l}\text { Neuro Psychic } \\
\text { Adaptation }\end{array}$ & $36 \pm 2.8$ & $25 \pm 3.5^{* *}$ & $35 \pm 2.2$ & $21 \pm 2.8^{* *}$ & $34 \pm 2.5$ & $17 \pm 1.2^{*}$ \\
\hline Situational Anxiety & $40 \pm 0.6$ & $40 \pm 0.7$ & $44 \pm 0.9^{*}$ & $38 \pm 1.3^{*}$ & $38 \pm 0.6$ & $36 \pm 0.5^{*}$ \\
\hline Personal Anxiety & $43 \pm 0.5$ & $40 \pm 0.6$ & $43 \pm 0.8$ & $37 \pm 1.3^{*}$ & $42 \pm 0.6$ & $35 \pm 0.5^{*}$ \\
\hline Level of Social Frustration & $1.8 \pm 0.05$ & $1.8 \pm 0.08$ & $1.9 \pm 0.06^{* *}$ & $1.7 \pm 0.07$ & $2 \pm 0.08^{* *}$ & $1.6 \pm 0.05^{*}$ \\
\hline
\end{tabular}

The data showed that the average indices of Neuro Psychic Adaptation (NPA) in the surveyed girls are higher than in the boys within each group $(\mathrm{p}<0.05)$. At the same time, more than $40 \%$ of girls and $15 \%-20 \%$ of the young men of the groups surveyed registered signs of a disturbance of Neuro Psychic Adaptation. In young men indigenous subjects the average score of the NPA scale was significantly higher than that of the Magadan ones $(\mathrm{p}<0.05)$ (Table 1$)$.

The average group values of Situational and Personal Anxiety in the subjects were within the normal range. However, among the Aboriginals these indicators were significantly higher $(p<0.05)$ compared with the age mates from the 2nd and 3rd groups. The highest percentage of persons with pronounced Situational Anxiety was recorded in $42 \%$ of Caucasian girls and $25 \%$ of Aboriginal boys, in $29 \%$ of Aboriginal girls and $18 \%$ of the girls from the city of Magadan, and in $9 \%$ of male Caucasians from both groups. $44 \%$ of the girls from the 1 st and 2 nd groups and $35 \%$ of the girls from Magadan had high Personal Anxiety. Among young male subjects $21 \%, 15 \%$ and $6 \%$ from the three examined groups respectively, had high levels of anxiety.

Along with this, the Level of Social Frustration (LSF) among high school students that is the impossibility of satisfying certain needs had its own characteristics (Table 1). In girls the LSF index significantly increased from the 1st to the 3rd group $(p<0.05)$ while among young men, on the contrary, that index significantly decreased $(\mathrm{p}<0.05)$. In high school students from the 1st group, both girls and boys, the LSF index was significantly lower than in the 2 nd and 3rd groups $(p<0.05)$ (Table 1). 
The results of the study of various forms of aggression among high school students of different ethnic groups, both girls and boys, are presented in Figure 1 ( $a$ and $b$ ).

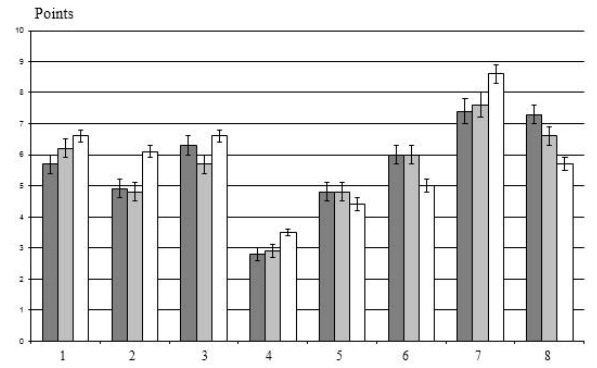

(a)

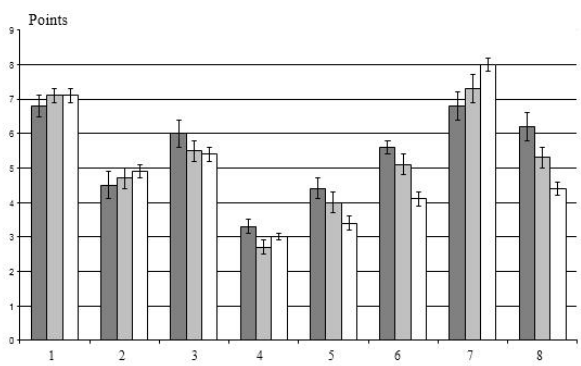

(b)

Figure 1. The severity of aggressive and hostile reactions in adolescents of different ethnic groups of northeast Russia (a -girls, b- boys).

1. Aborigines are highlighted in dark grey; 2. North born Caucasians of Evensk are highlighted in light grey; 3 . North born Caucasians of Magadan are highlighted in white color; 1 - Physical Aggression; 2- Indirect Aggression; 3- Irritation; 4-Negativity; 5- Resentment; 6- Suspicion; 7- Verbal Aggression; 8- Feeling of Guilt.

The data (Figure 1, a) showed that the girls of Magadan are mostly characterized by manifestations of aggressive reactions (Indirect Aggression, Verbal Aggression, Irritability) and Negativism. In the Caucasian girls from Evenks, as well as in the Aboriginal ones of the settlement, more pronounced Hostile and Auto-Aggressive Reactions (Suspicion and Feeling of Guilt) were observed. The highest rate of the Feeling of Guilt was recorded in the Aboriginal girls.

In figure $1 \mathrm{~b}$ we can see that among the Aboriginal and Caucasian young male residents from Evensk as well as among the girls of the settlement, Hostile and Auto-Aggressive Reactions (Resentment, Suspicion, and Feeling of Guilt) are more pronounced as compared to Magadan peers $(\mathrm{p}<0.05)$ (Figure 1,b). Moreover among Aboriginal boys as well as among Aboriginal girls, the indicator of the Feeling of Guilt is the highest among the peer subjects (Figure 1,a). In turn, the Magadan subjects, both girls and boys, were characterized by higher Verbal Aggression (Figure 1,b).

When analyzing the intergroup differences of aggressive reactions in the surveyed high school students, we can note the aggressiveness profiles of groups 1 and 2 that have proved themselves to be very close in both boys and girls (Figure $1, a, b$ ).

The girls and boys of the Aboriginal population differ from the Caucasian age mates of Evensk by a significantly greater Feeling of Guilt $(\mathrm{p}<0.05)$.

Aboriginal boys are more inherent in Negativism. Significantly more pronounced aggressive reactions (Physical Aggression, Indirect Aggression, and Verbal Aggression) and Negativism were observed in the Magadan female subjects, compared with the Aboriginal peers $(p<0.05)$. The aboriginal girls showed hostile (suspicious) and auto-aggressive (guilt) reactions $(p<0.05)$ to be significantly more frequent.

\section{Discussion}

Our study has showed that the formation of the adolescents' emotional sphere in the North is undoubtedly influenced not only by the climatic and socio-economic environmental factors but also by ethnic features. Aboriginals proved to experience more disorders in neuropsychic adaptation, situation-caused and personal anxiety as well as social frustration, in comparison with European age mates. The girls of the city of Magadan and the boys of the Aboriginal population demonstrated themselves to be the most frustrated by various spheres of social functioning. Since frustration is one of the reasons for anxiety, irritability, aggressive reactions, and finally neurosis, we can say that there is a risk of disharmonious mental states in these groups, which can lead to a depressive state. 
Indicators of Suspicion, Resentment and the Feeling of Guilt reflect neurotic reactions and serve as an indicator of the general instability of the relationship of an individual with surrounding people [23]. The level of Auto-Aggression, according to the reference, is directly related to introversion, pedantry, as well as depression, neurotic character of the personality [23-25] and is a risk factor for the development of suicidal behavior.

The high verbal form of aggressive behavior in adolescence may be caused by the contradiction of intrapersonal development such as the combination of high Personal and Situational Anxiety with high levels of self-esteem and aspirations [24].

There are intergroup differences in the aggressiveness profile of older adolescents living in the remote settlement vs. the regional center. It is shown that high school students in the remote settlement of Evensk, compared to their peers in Magadan, regardless of gender and ethnicity, are characterized by more pronounced hostile and auto-aggressive reactions. In adolescents of the Aboriginal population, as compared with their age mate Caucasians, the indicators of impairment in the field of Neuro Psychic Adaptation, Situational and Personal Anxiety, and Social Frustration are significantly more pronounced. Besides, a rather high percentage of examined girls with low levels of neuropsychological stability and high Anxiety cause concern. Their psychic reserve expenses are elevated. This requires the closest attention of mental health professionals.

Author Contributions: For research articles Conceptualization, B.T.P.; Methodology, B.T.P.; Resources, B.T.P., B.O.P.; Writing-Original Draft Preparation, B.T.P., B.O.P.; Writing-Review \& Editing, B.T.P.; Visualization, B.T.P.; Supervision, B.T.P.; Project Administration, B.T.P., B.O.P.

Funding: This research received no external funding.

Acknowledgments: This research did not receive any specific grant from funding agencies in the public, commercial, or not-for-profit sectors.

Conflicts of Interest: The authors declare no conflict of interest.

\section{References}

1. Kapur, Sh. Adolescence: the stage of transition. Horizons of Holistic Education. 2015, 2, 233-250.

2. Freud, A. Theory and Practice of Child Psychoanalysis. M., 1999. ISBN 5-04-003983-2

3. Khasnulin, V.I.; Leutin, V.P.; Chukhrova, M.G.; Gafarov, V.V. Ethnocultural Factors of Mental Adaptation of the Indigenous People of Siberia and the North in Modern Conditions. World of Science, Culture, Education. 2009, 6, 248-253.

4. Nikolaev, E.L. Crisis and Suicide: a Clinical and Psychological Analysis of Auto-Aggressive Behavior. Suicidology. 2015, 6, 54-61.

5. Beiter, R.; Nash, R.; McCrady, M.; Rhoades, D.; Linscomb, M.; Clarahan, M.; Sammut, S. The prevalence and correlates of depression, anxiety, and stress in a sample of college students. J. Affect. Disord. 2015, 173, 90-96.[CrossRef] [PubMed]

6. Eidemiller, E.G.; Dobryakov, I.V.; Nikolskaya, I.M. Family Diagnosis and Family Psychotherapy. Manual for Doctors and Psychologists. 2nd Ee., rev. and add. SPb .: Speech, 2006. - 352 p. ISBN 5-9268-0204-0

7. Stoddard, Joel; Stringaris, A.; Brotman, M. A.; Montville, D.; Pine D. S., Leibenluft, E. Irritability in child and adolescent anxiety disorders. Depression and anxiety. 2014, 31, 566-573. DOI 10.1002/da.22151

8. Bartosh, T.P.; Bartosh, O.P.; Mychko, M.V.; Disorders in the Psychoemotional Sphere of Senior Schoolchildren in Magadan. Bulletin of the Northeast Scuientific Center, Russian Academy of Sciences Far East Branch. 2011, 4, 24-29.

9. Bartosh, T.P.; Bartosh, O.P. Emotional health profiles observed in Magadan city adolescents of different ethnic origin. Tyumen Medical Journa. 2015, 17, 4, 7-13.

10. Semyonova, N.B.; Manchuk, V.T. Characteristic of the Emotional Sphere of Adolescents of the Indigenous Population of the Republic of Tyva. Social and Clinical Psychiatry. 2007, 3, 15-19.

11. Hill, D.L. Relationship between Sense of Belonging as Connectedness and Suicide in American Indians. Arch. Psychiatr. Nurs. 2009, 23, 65-74.

12. Lehti, V.; Niemela, S.; Hoven, C. et al. Mental Health, Substance Use and Suicidal Behavior among Young Indigenous People in the Arctic: Systematic Review. Soc. Sci. Med. 2009, 69, 1194-1203. 
13. Bjerregaard, P.; Curtis, T. Cultural change and mental health in Greenland: the association of childhood conditions,language, and urbanization with mental health and suicidal thoughts among the Inuit of Greenland. Social Science E Medicine. 2002, 54, 33-48.

14. Lubov, E.B.; Sumarokov, Yu.A.; Konoplenko, E.R.; Resilience and Risk Factors for Suicidal Behavior of the Indigenous Peoples of North Russia. Suicidology. 2015, 6, 3, 23-28.

15. DeCou, Ch. R.; Skewes, M. C.; Lo, E.D.S. Traditional living and cultural ways as protective factors against suicide: Perceptions of Alaska Native university students. Int. J. Circumpolar Health. 2013, 72, 1-5. http://dx.doi.org/10.3402/ijch.v72i0.20968

16. Qiao, N.;Bell, T.M. Indigenous Adolescents Suicidal Behaviors and Risk Factors: Evidence from the National Youth Risk Behavior Survey. Journal of Immigrant and Minority Health. 2017, 19, 590-597.

17. Semyonova, N.B. Features of the Emotional Sphere of the Indigenous Youth of the North as a Risk Factor for Suicidal Behavior. Suicidology. 2011, 2, 11-14.

18. Gvion,Y.; Apter, A. Suicide and Suicidal Behavior. Public Health Reviews. 2012,34, 2 Crossref

19. Cugura, T.; Boh, J.; Zupanc, T.; Pregelj, P.; Paska, A. Differences in SNP genotype distributions between complex and simple suicides. International Journal of Legal Medicine. 2018, 132, 6, 1595-1601. 10.1007/s00414-018-1820-x, $\underline{\text { Crossref }}$

20. Bortolato, M.; Pivac, N.; Seler, D.M.; Perkovic, N.; Pessia, M.; Di Giovanni, G. The role of the serotonergic system at the interface of aggression and suicide. Neuroscience. 2013, 236, 160-185. Crossref

21. Conner, K.R.; Duberstein, P.R.; Conwell, Y.; Seidlitz, L.; Caine, E.D. Psychological vulnerability to completed suicide: A review of empirical studies Suicide and Life-Threatening Behavior. 2001, 31 (4), 367-385.

22. Gurvich, I.N. Test to determine neuro-psychic adaptation. Bulletin of hypnology and psychotherapy, 1992, 3, 46-53.

23. Prevention of Aggressive and Terrorist Manifestations in Adolescents: a Textbook for Teachers, School Psychologists, Parents / Enikolopov, S.N. [et al.]; ed. by Sokovny, I.I. - 2nd ed., - Moscow: Enlightenment, 2002. 158. ISBN 5-09-014089-8

24. Semenyuk, L.M. Psychological Features of Aggressive Behavior of Adolescents and the Conditions for its Correction. - Moscow: Moscow Psychological and Social Institute: Flint, 1998, 96.

25. Björkqvist, K. Gender differences in aggression. Current Opinion in Psychology 2017, 19, $39-42$. DOI: $\underline{10.1016 / j . c o p s y c .2017 .03 .030}$ 